\title{
Continuous Assessment of a Stented Coronary Artery Using a Pressure Wire During Percutaneous Pulmonary Valve Implantation
}

\author{
Brian A. Boe, MD*, Sharon L. Cheatham, PhD, APRN, ACNP-BC, FSCAl, John P. Cheatham, MD, MSCAI
}

The Heart Center, Nationwide Children's Hospital, Columbus, Ohio, USA

\begin{abstract}
A 52-year-old woman with tetralogy of Fallot status post-complete surgical repair with infundibular resection, pulmonary valvotomy, and patch closure of the ventricular septal defect presented with severe pulmonary regurgitation and depressed right ventricular function. During intended percutaneous pulmonary valve implantation (PPVI), multiple stenotic lesions were discovered in her left anterior descending (LAD) coronary artery, and the procedure was aborted. She underwent treatment of these lesions using drug-eluting stents by our adult interventional colleagues and returned to the congenital catheterization laboratory for PPVI 18 months following her initial procedure. Given the potential risk of crush injury to the coronary arterial stents, the distal LAD artery was continuously monitored during the procedure via a pressure wire with the capability of re-expanding the stent if needed. Copyright $\odot 2017$ Science International Corp.
\end{abstract}

\section{Key Words}

Congenital catheterization - Intervention - Valve implantation

\section{Introduction}

Percutaneous pulmonary valve implantation (PPVI) is an effective method for treating right ventricular outflow tract (RVOT) obstruction and regurgitation in patients with congenital heart disease $[1,2,3]$. A rare but catastrophic complication of PPVI is mechanical coronary artery compression due to implantation of

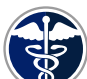

Fax +1 2037853346

E-Mail: jshd@scienceinternational.org

http://structuralheartdisease.org/ (c) 2017 Journal of Structural Heart Disease Published by Science International Corp. ISSN 2326-4004

Accessible online at: http://structuralheartdisease.org/ a stent and/or valve within the RVOT [4]. Coronary artery testing is recommended during balloon angioplasty of the RVOT to assess coronary artery compression or distortion. However, the presence of an existing coronary artery stent may render coronary artery testing with balloon angioplasty/compliance testing a higher risk procedure. Here, we report the first use of a pressure wire within a stented left anterior descending (LAD) coronary artery in close proximity to the RVOT during PPVI to assess for coronary artery stent compromise and to maintain access for treatment of compression with redilation of the stent or re-stent if necessary.

\section{Case Presentation}

A 52-year-old woman with tetralogy of Fallot presented to our adult congenital cardiology program for evaluation. She underwent complete surgical repair at 8 years of age consisting of infundibular resection, pulmonary valvotomy, and patch closure of a ventricular septal defect. Her residual atrial septal defect was closed with a CardioSEAL ${ }^{\text {TM }}$ Occlusion Device (Nitinol Medical Technologies, Ind., Boston, Massachusetts) at 38 years of age. Past medical history was also significant for diabetes mellitus and hypertension. As a result of her surgical palliation, the patient had severe pulmonary valve regurgitation with decreased right ventricular function and was referred for PPVI.

* Corresponding Author:

Brian Boe, MD

The Heart Center

Nationwide Children's Hospita

700 Children's Drive Columbus, OH 43205-2664, USA

Tel.: +1 614722 2459; Fax: +1 614722 5030; E-Mail: brian.boe@nationwidechildrens.org 

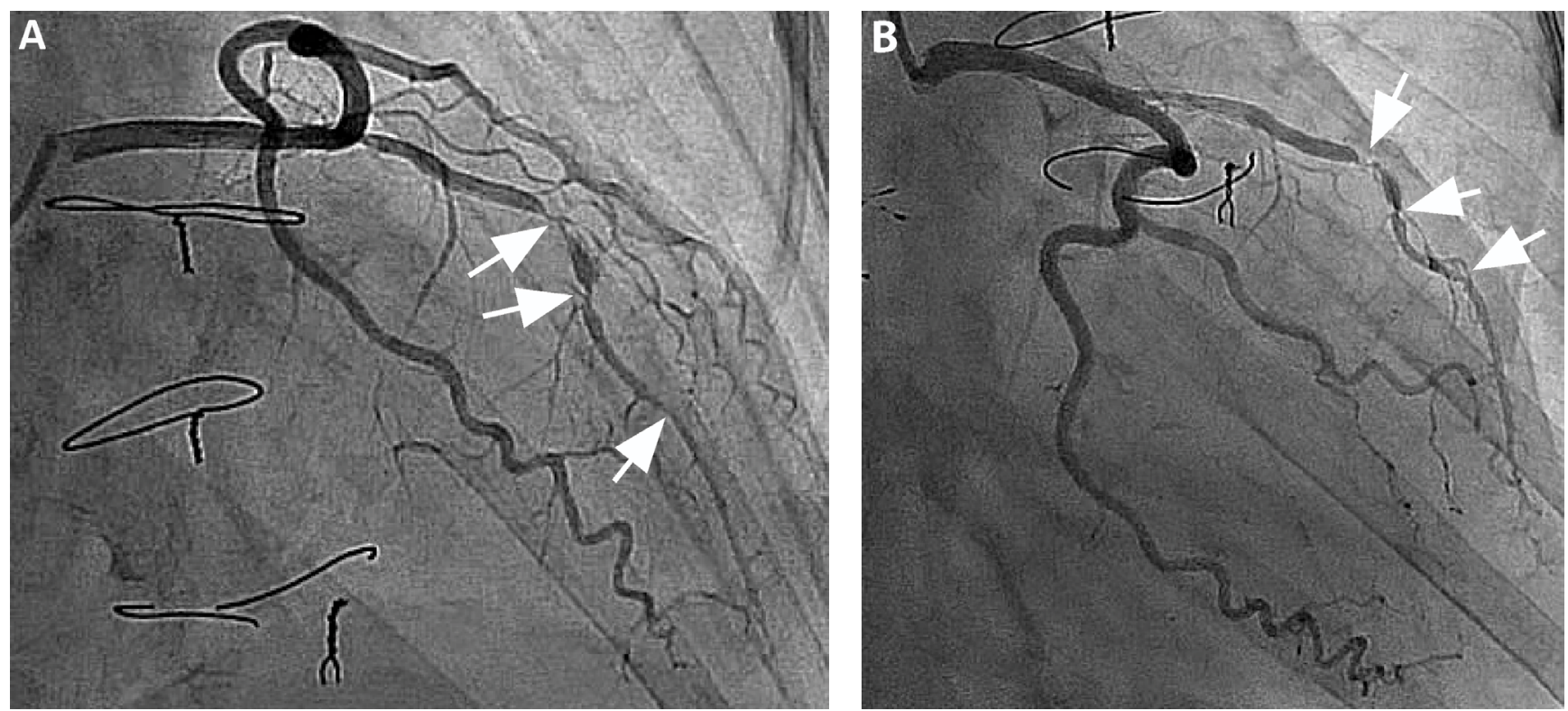

Figure 1. Selective left coronary angiography performed during the first catheterization in anteroposterior (Panel $A)$ and right anterior oblique/caudal (Panel B) projections. There were a total of three stenotic lesions (arrows) along the left anterior descending (LAD) artery with near occlusion of the vessel.

Prior to RVOT intervention, multiple stenotic lesions were discovered within her LAD, and the procedure was aborted (Figure 1). Over the next few months, the patient underwent percutaneous coronary intervention by our adult interventional colleagues with a total of three drug-eluting stents placed along her proximal, mid, and distal LAD. After surveillance coronary angiography revealed no residual coronary arterial narrowing, the now 54-year-old patient was referred back to the congenital cardiac catheterization laboratory for PPVI.

Following hemodynamic evaluation, three-dimensional rotational angiography was performed for the RVOT with simultaneous selective left coronary angiography to delineate the spatial relationship between the RVOT and left coronary artery (Videos 1 and 2 Figure 2). The course of the left main coronary artery was immediately posterior to the RVOT but superior to the intended transcatheter valve landing zone at the level of the native pulmonary valve annulus. The stented LAD was anterior and leftward to the RVOT. Angiography of the RVOT showed a dilated RVOT that narrowed to 16.7 $\times 20.1 \mathrm{~mm}$ at the level of the native pulmonary valve (Video 3, Figure 3). We next planned on performing

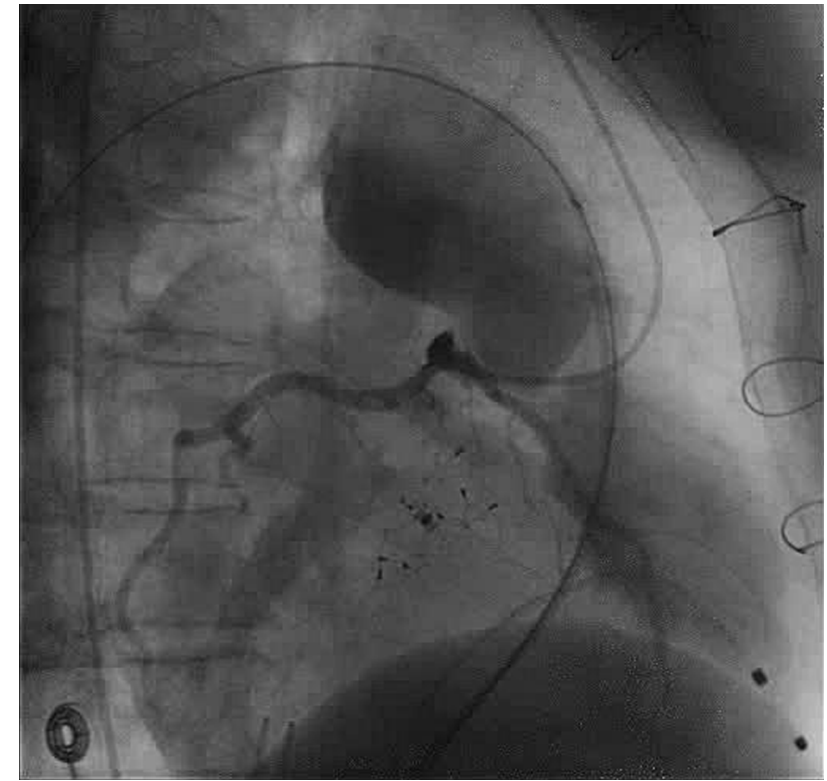

Video 1. Three-dimensional rotational angiography performed via a simultaneous power injection in the right ventricular outflow tract and hand injection of the left main coronary artery. The narrowing of the right ventricular outflow tract was located at the native pulmonary valve annulus with the left main coronary artery running immediately behind the right ventricular outflow tract. The stented LAD coursed leftward and posterior to the right ventricular outflow tract. View supplemental video at https://doi.org/10.12945/j.jshd.2017.017.17.vid.01. 


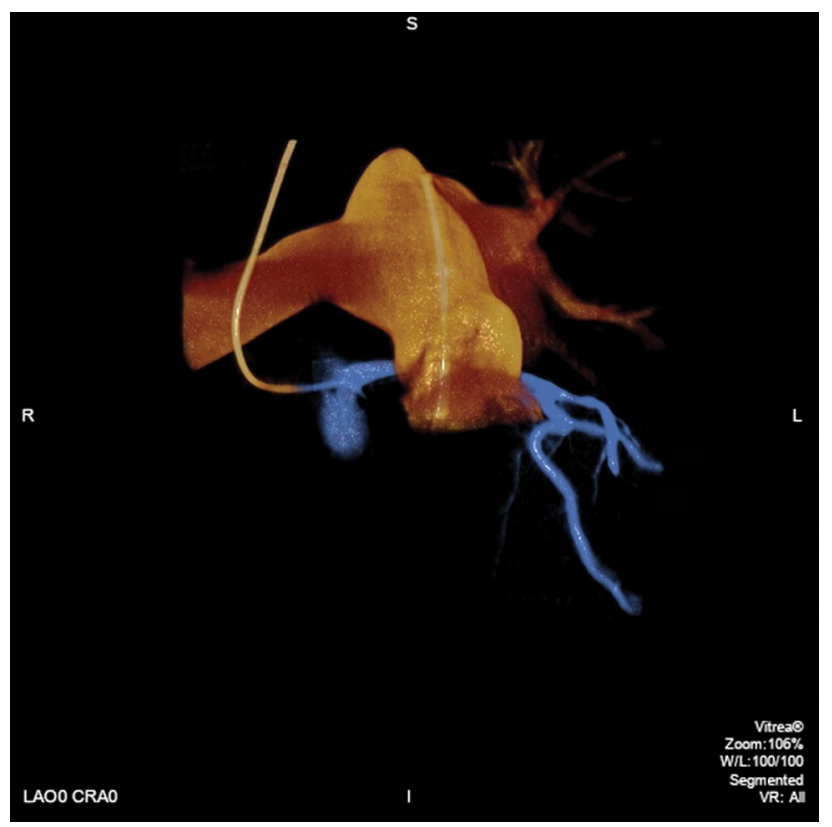

Video 2. Three-dimensional rotational reconstruction of the right ventricular outflow tract (yellow) and left coronary artery (blue) from dual injection three-dimensional rotational angiography. The left main coronary artery ran posterior to the outflow tract and was superior to the intended valve implantation site at the level of the native pulmonary valve annulus. The LAD coursed leftward and posterior to the right ventricular outflow tract. View supplemental video at https://doi.org/10.12945/j. jshd.2017.017.17.vid.02. balloon sizing of the RVOT with a low-pressure balloon. Given the risk of coronary stent compression with balloon angioplasty, stent implantation, and PPVI within the RVOT, we decided to continuously monitor distal LAD pressure during the intervention. This plan was discussed with our adult interventional colleagues, who were prepared to provide support as needed.

A 6-F JL-4 Guiding catheter (Cordis ${ }^{\circledR}$, Milpitas, California) was used to cannulate the left main coronary artery, and a 0.014" PrimeWire Prestige ${ }^{\circledR}$ PLUS pressure guide wire (Volcano Co., San Diego, California) was positioned in the distal LAD (Video 4, Figure 4). The measured pressure from the pressure wire was calibrated with the proximal coronary arterial pressure measured from the guide catheter. A $2.5 \times 15 \mathrm{~mm}$ Maverick coronary balloon (Boston Scientific Co., Marlborough, Massachusetts) was prepped and ready for use in the case of a crush injury to a coronary artery stent during RVOT intervention.

Sizing of the RVOT was performed using a $25 \mathrm{~mm} \times 4 \mathrm{~cm}$ Tyshak II balloon (B. Braun Medical Inc., Bethlehem, Pennsylvania) inflated to 1 atm. Selective left coronary angiography and continuous LAD pressure monitoring was performed during balloon sizing of the RVOT. Both the proximal left coronary
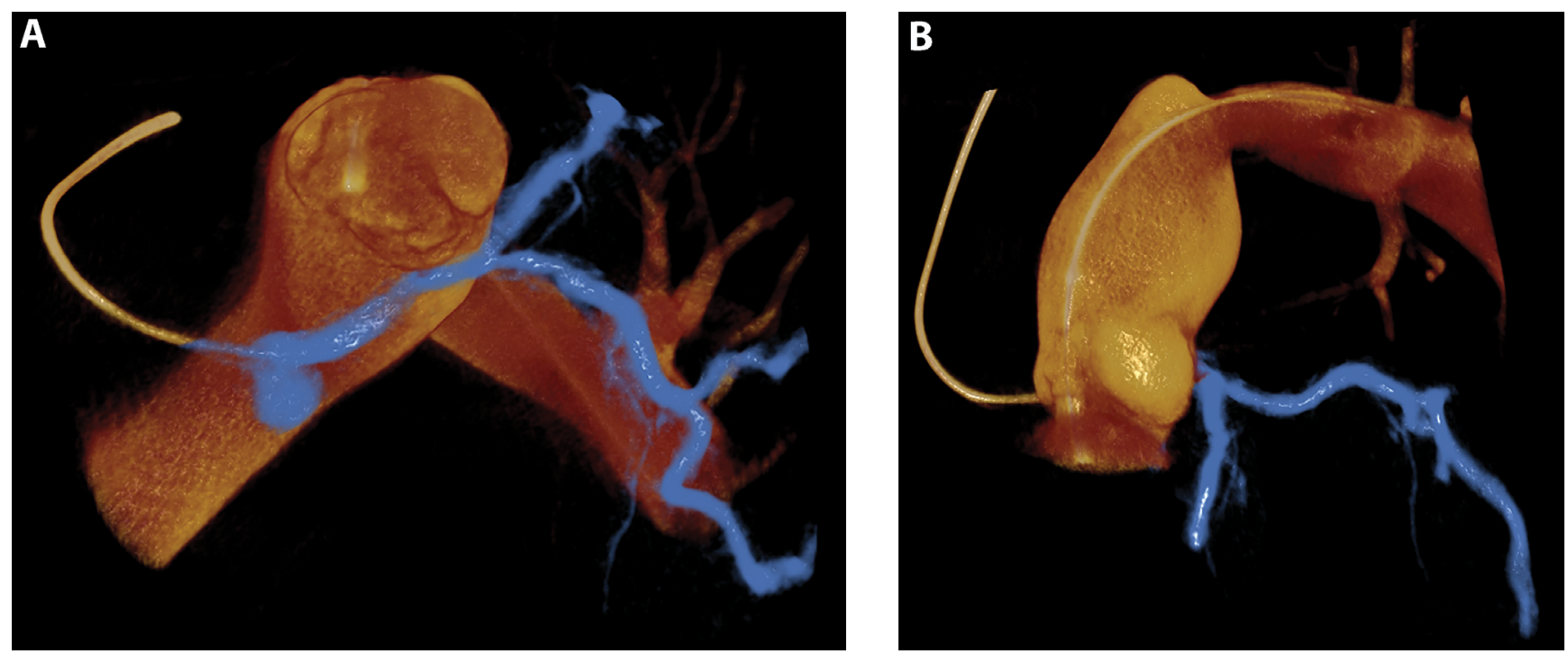

Figure 2. Three-dimensional rotational reconstruction of the right ventricular outflow tract (yellow) and left coronary artery (blue) in steep caudal (Panel A) and left anterior oblique (Panel B) projections from a dual injection three-dimensional rotational angiogram. The left main coronary artery ran posterior to the outflow tract and was superior to the intended valve implantation site at the level of the native pulmonary valve annulus. The LAD coursed leftward and posterior to the right ventricular outflow tract. 

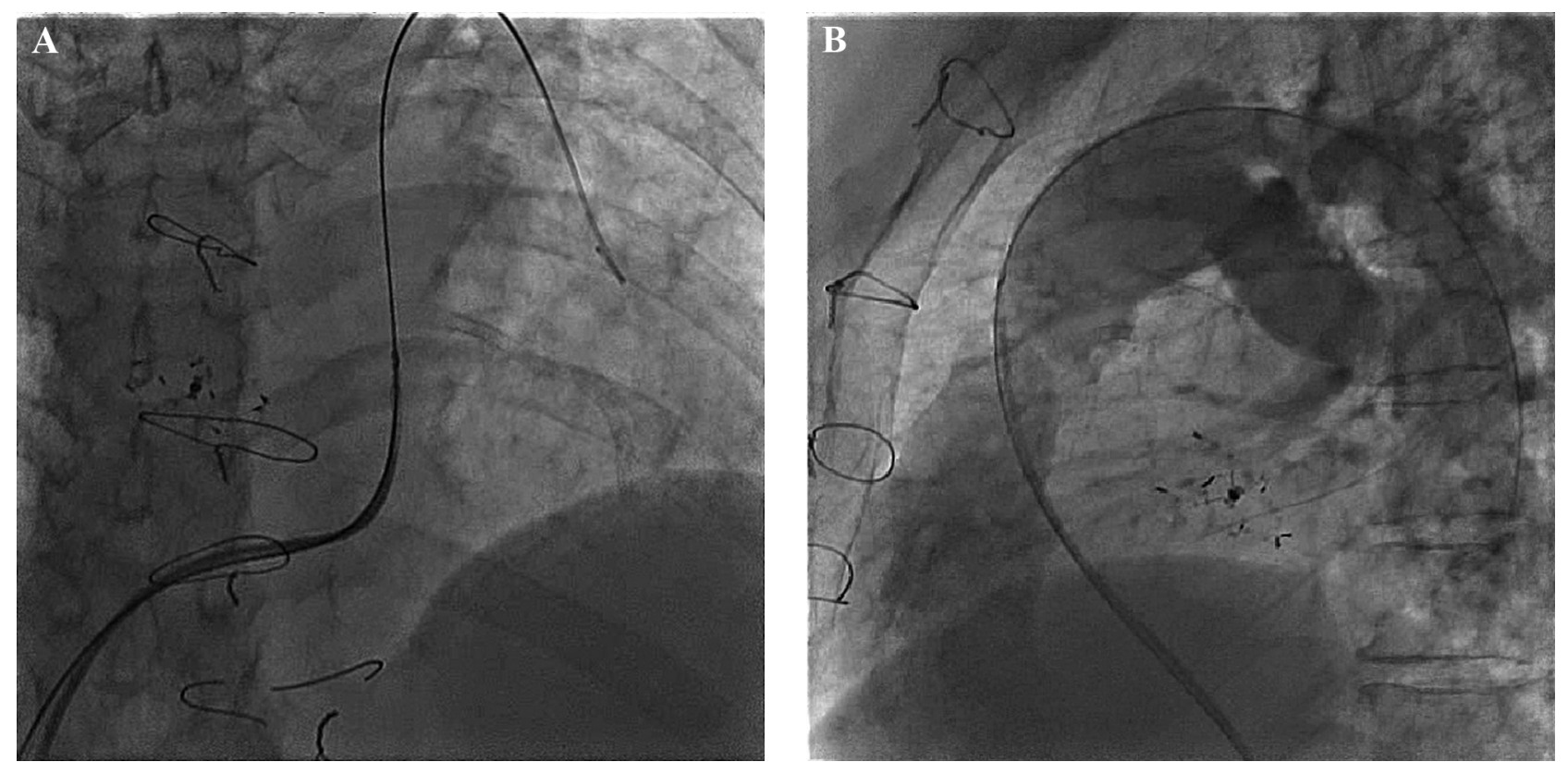

Video 3. Angiography of the right ventricular outflow tract in the anteroposterior (Panel A) and lateral (Panel B) projections. The narrowing of the right ventricular outflow tract occurred at the native pulmonary valve annulus. View supplemental video at https:// doi.org/10.12945/j.jshd.2017.017.17.vid.03A and https://doi.org/10.12945/j.jshd.2017.017.17.vid.03B.
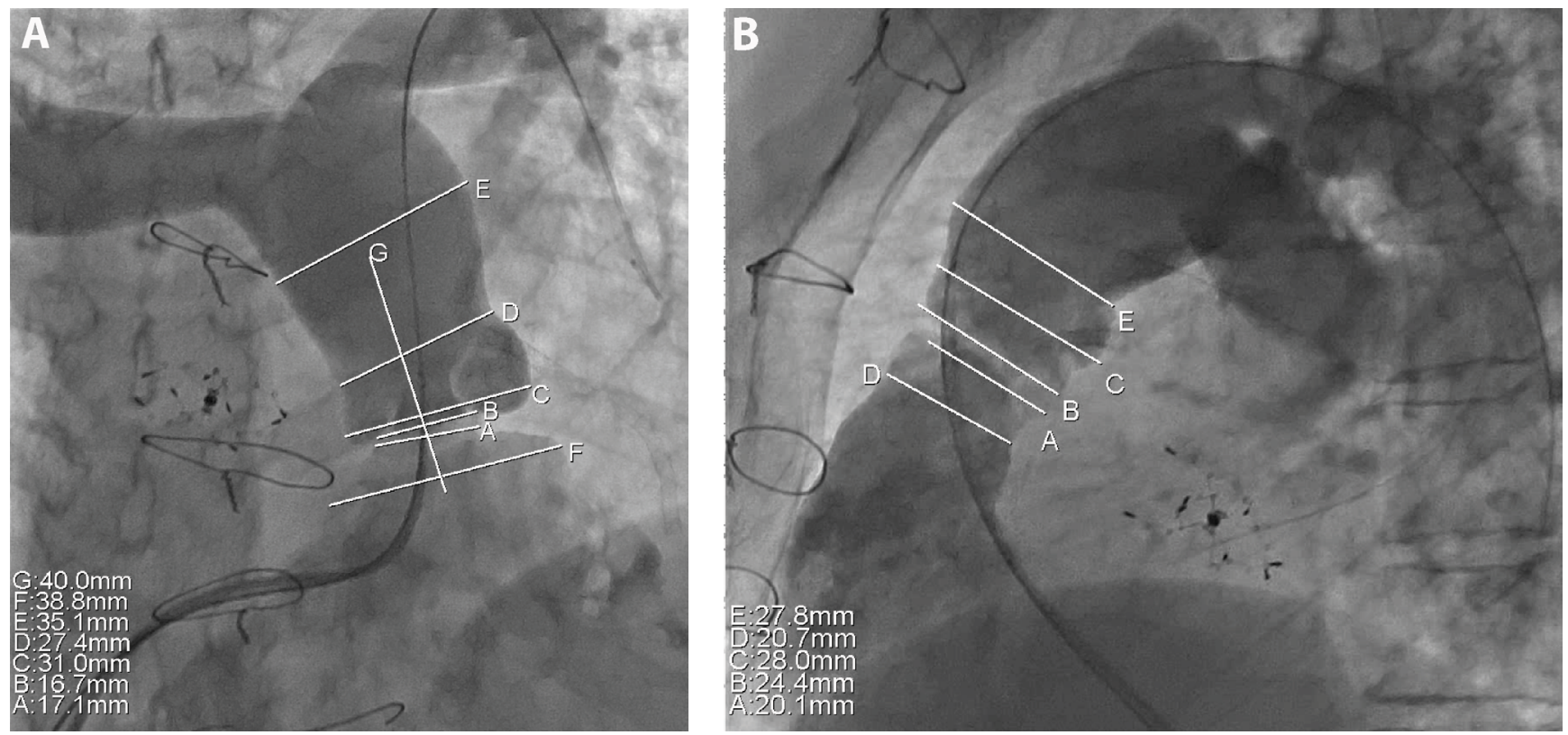

Figure 3. Angiography of the right ventricular outflow tract in the anteroposterior (Panel $A$ ) and lateral (Panel B) projections with measurements. The narrowing at the native pulmonary valve annulus measured $17.1 \times 20.1 \mathrm{~mm}$ in both projections.

arterial and distal LAD coronary arterial pressures decreased equally and simultaneously during inflation of the sizing balloon and completely recovered to baseline with balloon deflation (Figure 5).
No coronary arterial compression was demonstrated by angiography. There was a $19.8-\mathrm{mm}$ waist on the sizing balloon, and pre-stenting of the RVOT was completed with two Palmaz 3110 XL stents (Cordis ${ }^{\circledR}$, 


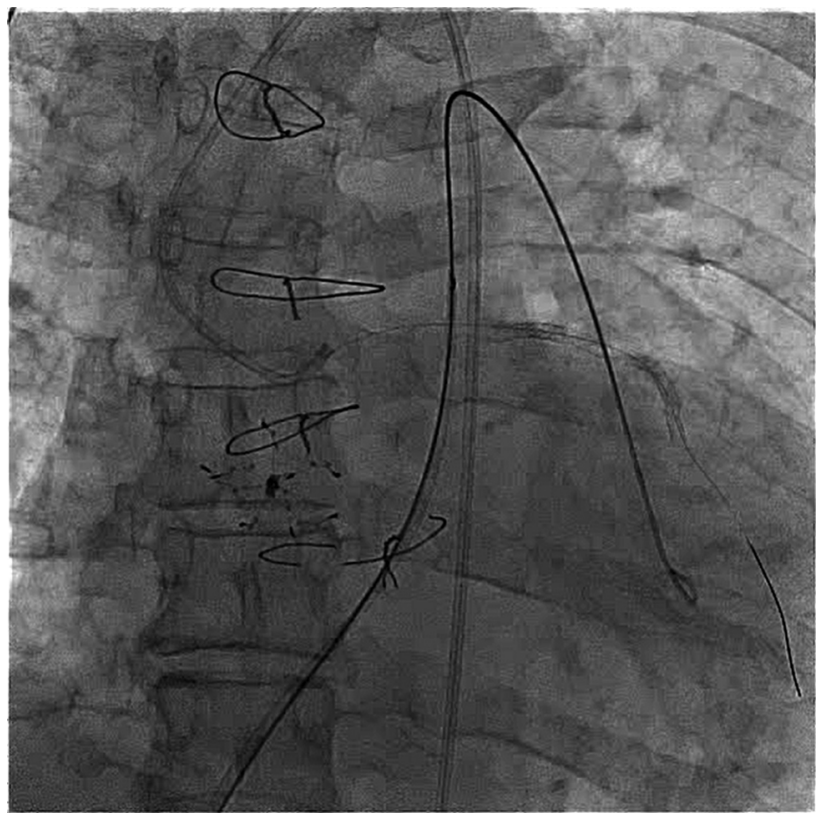

Video 4. Selective left coronary angiography showing the tip of the pressure wire positioned in the LAD distal to the previously placed stents. View supplemental video at https://doi. org/10.12945/j.jshd.2017.017.17.vid.04.
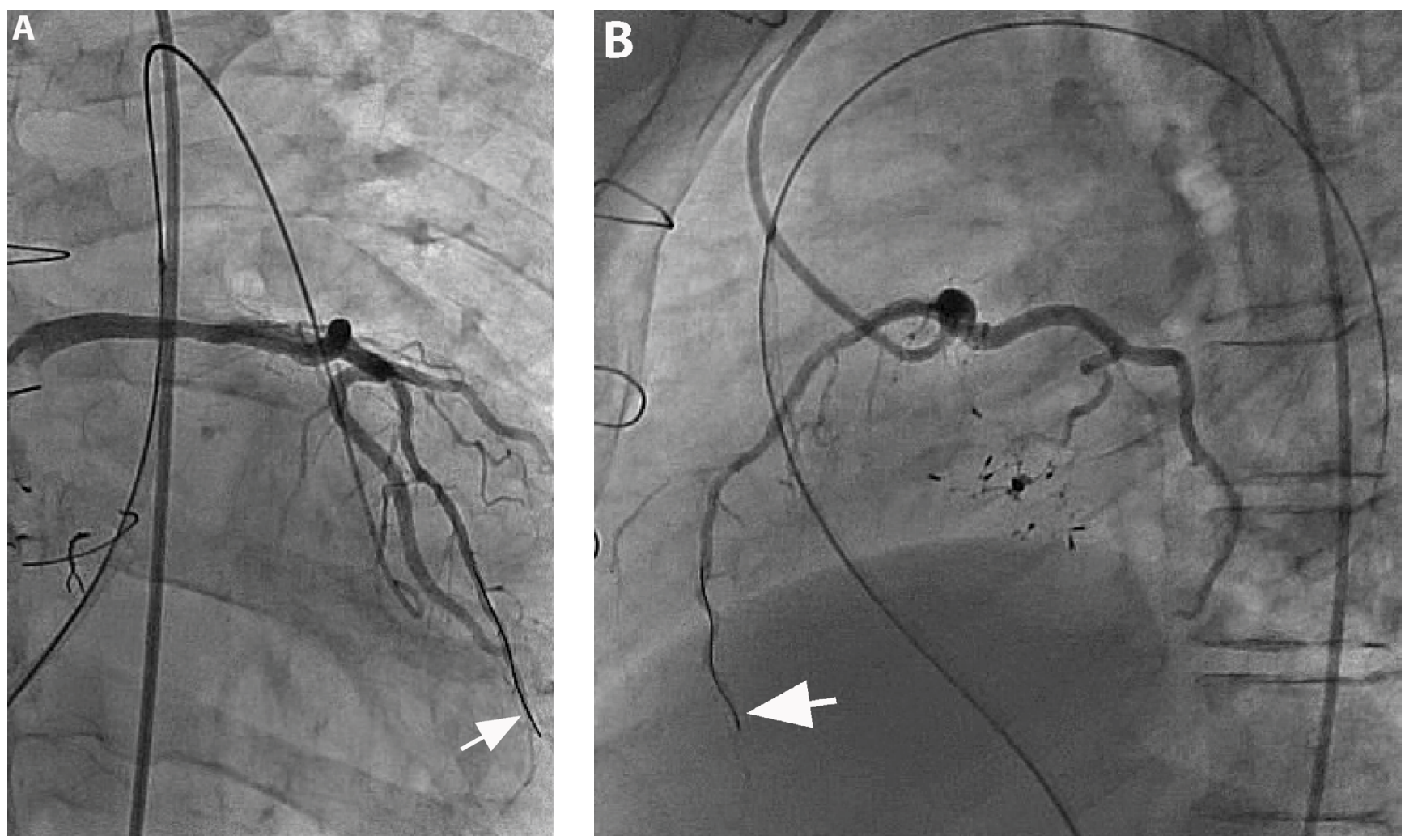

Figure 4. Anteroposterior (Panel $A$ ) and lateral (Panel B) projections of selective left coronary angiography showing the pressure wire (arrow) positioned in the distal LAD artery distal to the previously placed drug-eluting coronary stents.

Boe, B. A. et al.

CA Pressure Wire During PPVI
Milpitas, California) delivered on $22 \mathrm{~mm} \times 3.5 \mathrm{~cm}$ BIB balloons (NuMED, Inc., Hopkinton, New York) without a significant pressure difference across the LAD stent. The stents overlapped at the RVOT narrowing, which was the intended landing zone for the valve. A PB1018 Melody Transcatheter Pulmonary Valve ${ }^{\circledR}$ (TPV) (Medtronic, Minneapolis, Minnesota) was delivered via a 22-mm Ensemble ${ }^{\circledR}$ Transcatheter Valve Delivery System (Medtronic) coaxially within the Palmaz stents. Distal LAD coronary arterial pressure remained stable during the RVOT intervention. Repeat selective left coronary arterial angiography was performed following Melody TPV implantation, which showed no compression of the coronary artery (Video 5, Figure 6). The pressure wire and $\mathrm{J}$ guide catheter were then removed. Intracardiac echocardiographic evaluation of the Melody TPV revealed trivial central valvar regurgitation and no paravalvar leak (Video 6). The patient tolerated the procedure without complication and was discharged home on Aspirin $325 \mathrm{mg}$ and Clopidogrel $75 \mathrm{mg}$ daily. 

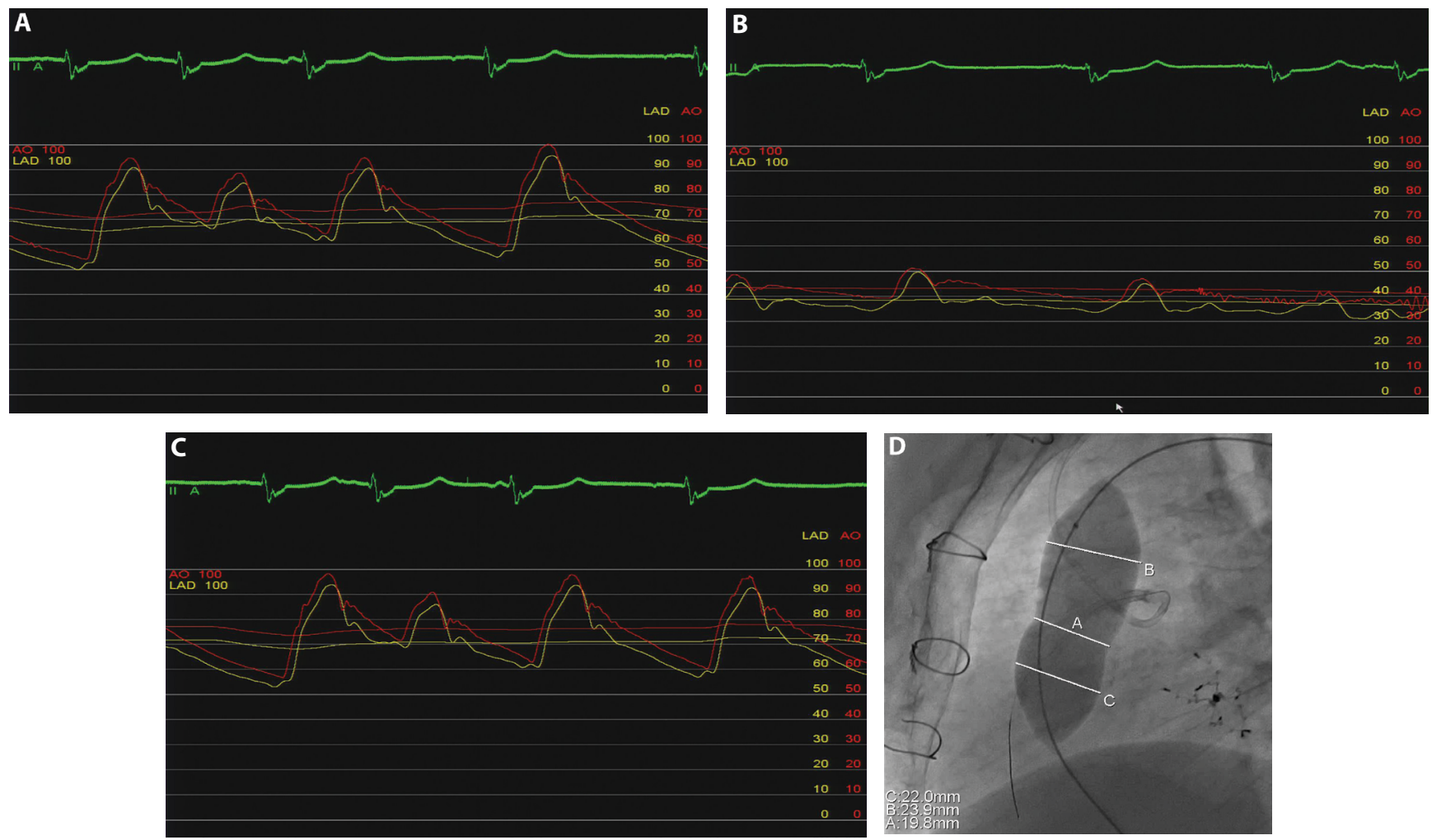

Figure 5. Continuous pressure monitoring of the proximal left main coronary artery (red) and distal LAD artery (yellow). At baseline (Panel A), the pressure in the LAD was slightly lower than the left main pressure. With balloon sizing of the RVOT (Panel B), both pressures decreased equally and returned to baseline upon deflation of the sizing balloon (Panel $C$ ). The lateral projection of the balloon sizing (Panel D) showed a balloon waist of $19.8 \mathrm{~mm}$ in diameter inferior to the left main coronary artery.

\section{Discussion}

Coronary artery compression during PPVI has been reported in multiple case series with outcomes varying from symptomatic acute coronary syndrome to cardiac arrest $[5,6,7,8,9,10,11]$. Morray and colleagues retrospectively evaluated coronary artery testing in 404 patients referred for PPVI in a multi-institutional study [4]. The risk of coronary artery compression in the study was $4.7 \%$ for all patients, with a risk of $71 \%$ for patients with abnormal coronary artery anatomy (i.e., left coronary artery arising from the right coronary artery, status post-Ross procedure). Additional risk factors for coronary artery compression included tetralogy of Fallot and transposition of the great arteries. Given this potential catastrophic outcome, coronary arterial testing with a balloon of equal size to the intended pre-stent implantation balloon is recommended and is the standard of care during PPVI. Although coronary artery testing provides good in- formation about the relationship of the coronary arteries to the RVOT, it cannot completely predict the final interaction between the patient's anatomy, pre-stents, and TPV. A recent study used three-dimensional rotational angiography to improve our understanding of coronary artery anatomy during PPVI [12]. In our case, both two-dimensional and three-dimensional angiography were used to evaluate the relationship between the stented left coronary artery and the RVOT prior to any intervention.

The accepted technique of coronary artery testing during balloon angioplasty of the RVOT is effective if the compression or distortion of the coronary artery is relieved by deflation of the balloon. However, with a stent already present in the at-risk $L A D$, deflating the balloon may not relieve the coronary artery compression. A stent implanted within the RVOT or coronary artery may prevent reversible coronary arterial compression. Here, we describe the first PPVI in a patient with coronary arterial stents that were 


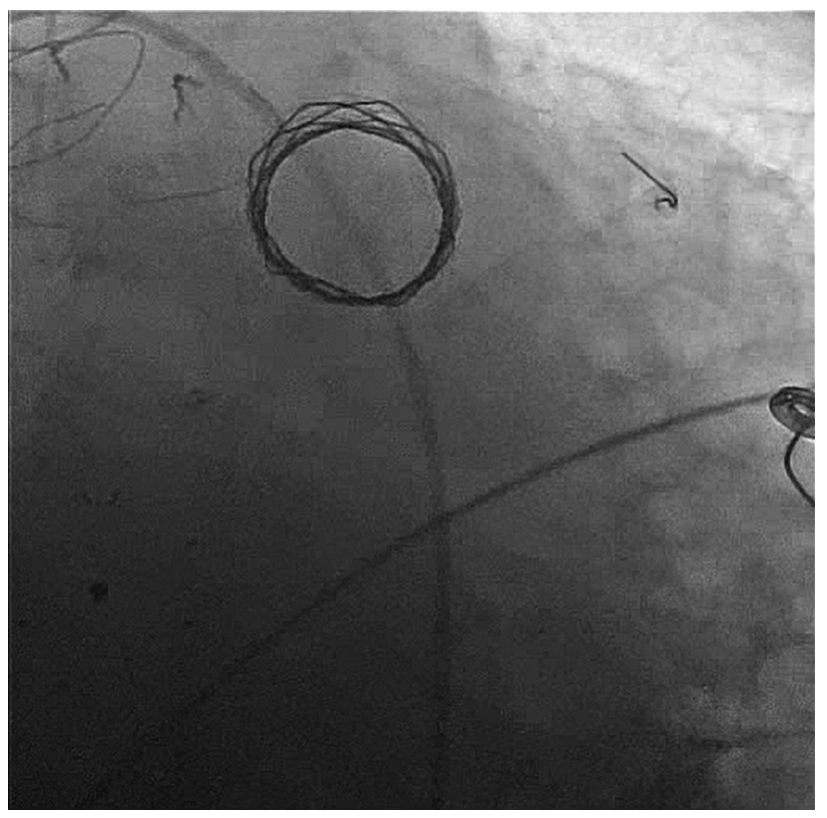

Video 5. Selective left coronary angiography following Melody TPV implantation at steep caudal projections showing no significant coronary arterial narrowing after PPVI. The pressure wire was positioned in the distal LAD. View supplemental video at https://doi.org/10.12945/j.jshd.2017.017.17.vid.05.

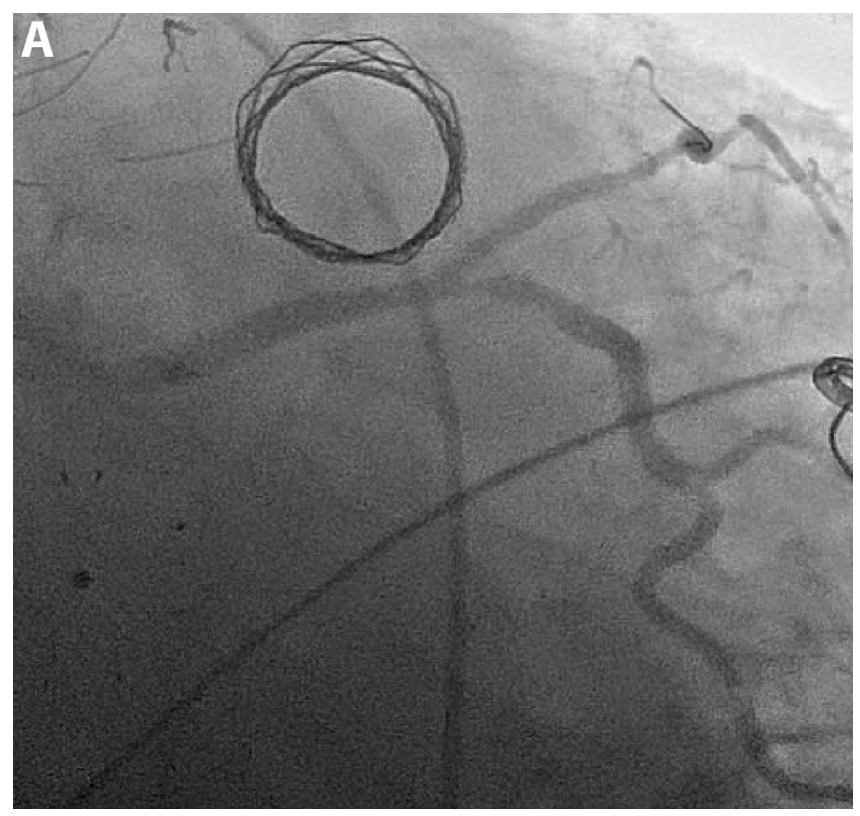

Figure 6. Selective left coronary angiography following Melody TPV implantation at steep caudal (Panel A) and left anterior oblique (Panel B) projections. No significant coronary arterial narrowing was seen following PPVI.

continuously monitored via a pressure wire during the intervention. Although the left coronary artery appeared remote from the implantation site, there

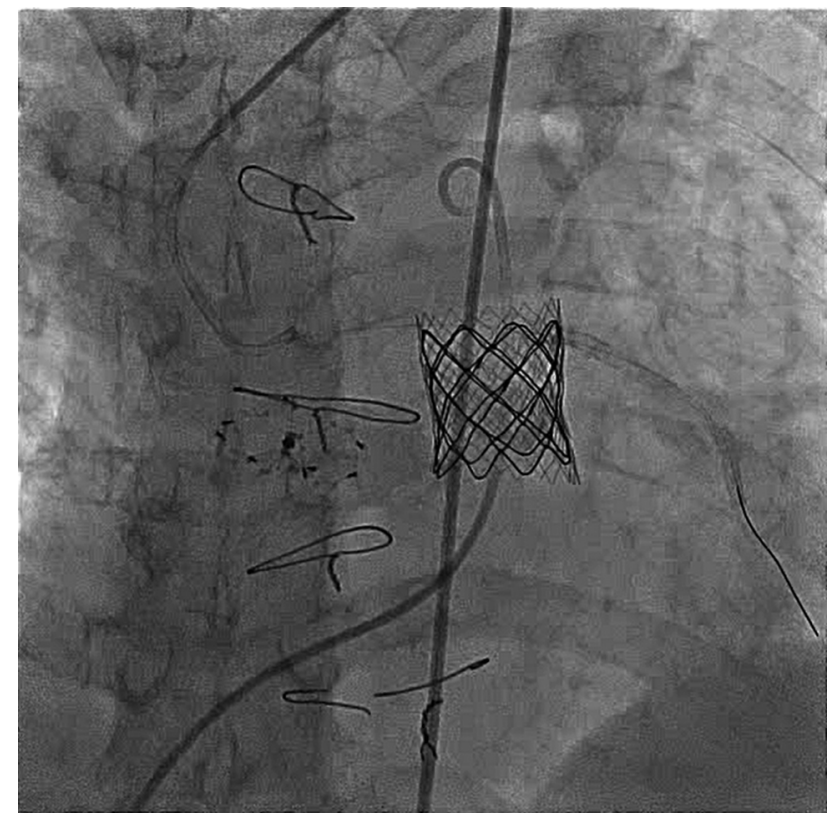

Video 6. Main pulmonary artery angiography following Melody TPV implantation demonstrating trivial central valvar regurgitation with a catheter through the valve and no paravalvar leak. View supplemental video at https://doi.org/10.12945/j. jshd.2017.017.17.vid.06.

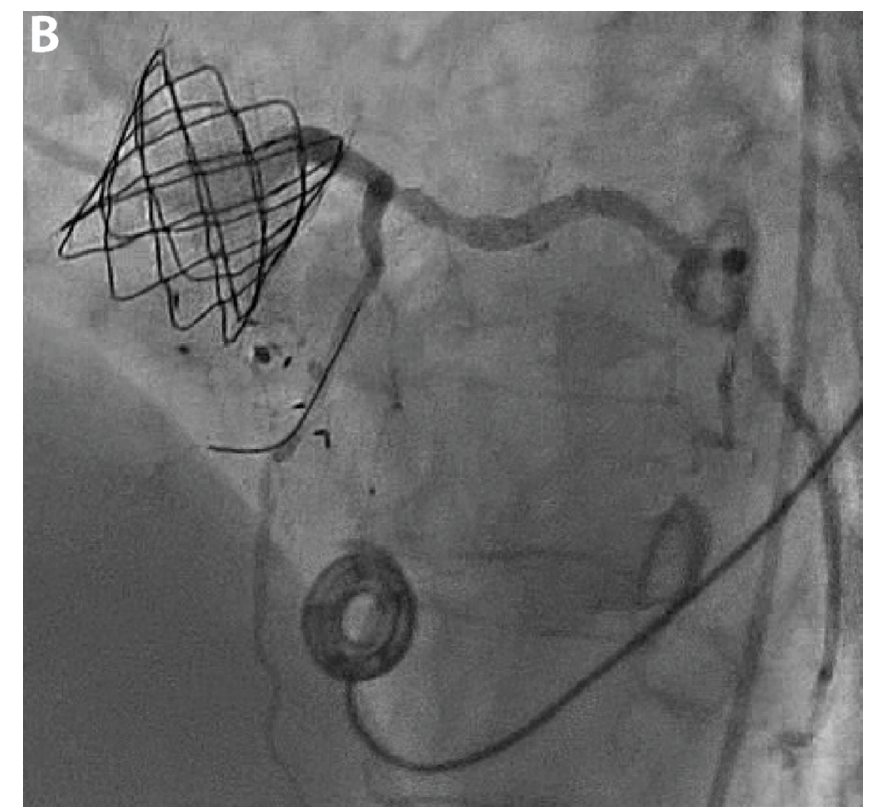

were potential masses (e.g., calcification, scar tissue) in addition to the pre-stents that could result in coronary artery compression. Continuous distal LAD pres- 
sure monitoring provided a constant assessment of coronary perfusion during the intervention and not just during angiographic balloon testing of the RVOT. As expected, pressures in both the proximal left main and distal LAD coronary arteries equally decreased with obstruction of the RVOT during balloon compliance testing, stent implantation, and PPVI, which resulted in a temporary decrease in left ventricular preload. In addition, both pressures recovered equally upon deflation of the balloons. Coronary artery stent compression would have been identified if either of the two following scenarios were present following balloon deflation: (1) a discrepancy between the two pressure waveforms indicating coronary artery stenosis or (2) both pressures not returning to baseline values as a result of acute left ventricular dysfunction. Had there been evidence of coronary artery compression, the $\mathrm{J}$ guide catheter positioned in the left main coronary artery would have allowed us to advance the prepped coronary balloon over the pressure wire to re-expand the stent.

Currently, the estimated number of adults with congenital heart disease in the United States is greater than 1 million [13]. As the congenital heart disease patient population ages, there will be an increasing number of patients with combined acquired cardiovascular disease in addition to their underlying congenital heart disease. With technological advancements in transcatheter therapies, a greater proportion of this patient population will receive percutaneous treatment in the catheterization labo- ratory. The interventional cardiologist must be mindful of both types of heart disease in the older patient. This procedure was performed in the congenital cardiac catheterization laboratory given the need for biplane imaging during PPVI. Our adult interventional colleagues were prepared to provide any assistance in the event of a coronary intervention. Adult congenital heart disease programs have bridged the gap between pediatric and adult cardiac care and can often assist in the planning of complicated interventional procedures in adult congenital heart disease patients. Close collaboration between congenital and adult interventional cardiology is needed to provide the best care to this patient population.

In conclusion, coronary artery compression is a risk of PPVI and should be routinely evaluated. Continuous coronary arterial pressure monitoring via a pressure wire can facilitate PPVI in high-risk patients with coronary arterial stents. Given the risk of coronary artery stent compression, these high-risk procedures should be performed with support from adult interventional cardiology.

\section{Conflict of Interest}

The authors have no conflict of interest relevant to this publication.

\section{Comment on this Article or Ask a Question}

\section{References}

1. Zahn EM, Hellenbrand WE, Lock JE, McElhinney DB. Implantation of the melody transcatheter pulmonary valve in patients with a dysfunctional right ventricular outflow tract conduit early results from the u.s. Clinical trial. J Am Coll Cardiol. 2009;54:1722-1729. DOI: 10.1016/j. jacc.2009.06.034

2. McElhinney DB, Hellenbrand WE, Zahn EM, Jones TK, Cheatham JP, Lock JE, et al. Shortand medium-term outcomes after transcatheter pulmonary valve placement in the expanded multicenter US melody valve trial. Circulation. 2010;122:507-516. DOI: 10.1161/CIRCULATIONAHA.109.921692

3. Cheatham JP, Hellenbrand WE, Zahn EM, Jones TK, Berman DP, Vincent JA, et al. Clinical and hemodynamic outcomes up to 7 years after transcatheter pulmonary valve replacement in the US melody valve investigational device exemption trial. Circulation. 2015;131:1960-1970. DOI: 10.1161/ CIRCULATIONAHA.114.013588

4. Morray BH, McElhinney DB, Cheatham JP, Zahn EM, Berman DP, Sullivan PM, et al. Risk of coronary artery compression among patients referred for transcatheter pulmonary valve implantation: A multicenter experience. Circ Cardiovasc Interv. 2013;6:535-542. DOI: 10.1161/CIRCINTERVENTIONS.113.000202

5. Sridharan S, Coats L, Khambadkone S, Taylor AM, Bonhoeffer P. Images in cardiovascular medicine. Transcatheter right ventricular outflow tract intervention: The risk to the coronary circulation. Circulation. 2006;113:e934-e935. DOI: 10.1161/CIRCULATIONAHA.105.599514

6. Divekar AA, Lee JJ, Tymchak WJ, Rutledge JM. Percutaneous coronary intervention for extrinsic coronary compression after pulmonary valve replacement. Catheter Cardiovasc Interv. 2006;67:482-484. DOI: 10.1002/ccd.20620

7. Kostolny M, Tsang V, Nordmeyer J, Van Doorn C, Frigiola A, Khambadkone S, et al. Rescue surgery following percutaneous pulmonary valve implantation. Eur J Cardiothorac Surg. 2008;33:607-612. DOI: 10.1016/j.ejcts.2007.12.034

8. Eicken A, Ewert P, Hager A, Peters B, Fratz S, Kuehne $\mathrm{T}$, et al. Percutaneous pulmonary valve implantation: Two-centre experience with more than 100 patients. Eur Heart J. 
2011;32:1260-1265. DOI: 10.1093/eurheartj/ ehq520

9. Biermann D, Schonebeck J, Rebel M, Weil J, Dodge-Khatami A. Left coronary artery occlusion after percutaneous pulmonary valve implantation. Ann Thorac Surg. 2012;94:e7-e9. DOI: 10.1016/j.athoracsur.2012.01.022

10. Mauri L, Frigiola A, Butera G. Emergency surgery for extrinsic coronary compression after percutaneous pulmonary valve implantation. Cardiol Young. 2013;23:463-465. DOI: 10.1017/ S1047951112001187

11. Dehghani P, Kraushaar G, Taylor DA. Coronary artery compression three months after transcatheter pulmonary valve implantation. Catheter Cardiovasc Interv. 2015;85:611-614. DOI: 10.1002/ ccd. 25628

12. Pockett CR, Moore JW, El-Said HG. Three dimensional rotational angiography for assessment of coronary arteries during melody valve implantation: Introducing a technique that may improve outcomes. Neth Heart J. 2017;25:82-90. DOI: 10.1007/ s12471-016-0931-6

13. Gilboa SM, Devine OJ, Kucik JE, Oster ME, Riehle-Colarusso T, Nembhard WN, et al. Congenital heart defects in the United States: Estimating the magnitude of the affected population in 2010. Circulation. 2016;134:101-109. DOI: 10.1161/CIRCULATIONAHA.115.019307
Cite this article as: Boe BA, Cheatham SL, Cheatham JP. Continuous Assessment of a Stented Coronary Artery Using a Pressure Wire During Percutaneous Pulmonary Valve Implantation. Structural Heart Disease. 2017;4(3):119-127. DOI: https://doi. org/10.12945/j.jshd.2017.017.17 